\title{
Coated Wire Silver-Ion Selective Electrode Based on a $N, N^{\prime}$-Bis(2-thienylmethylene)-1,2-diaminobenzene
}

\author{
Hamid R. Zare, ${ }^{* \dagger}$ Masoud SAlavati-Niassary, $* *$ Farkhondeh MemarZadeh, $*$ \\ Mohammad MAZLOUM,**and Navid NASIRIZADEH* \\ *Department of Chemistry, Yazd University, Yazd, 89195-741, Iran \\ **Department of Chemistry, Kashan University, Kashan, Iran
}

\begin{abstract}
A novel membrane coated platinum-wire electrode (MCPWE) based on $N, N^{\prime}$-bis(2-thienylmethylene)-1,2diaminobenzene (BTMD) for highly selective determination of $\mathrm{Ag}^{+}$ion has been developed. The influences of membrane composition and $\mathrm{pH}$ on the potentiometric responses of electrode were investigated. The potentiometric responses are independent of the $\mathrm{pH}$ of the test solution in the range of 5.0-9.0. The electrode shows a linear response for $\mathrm{Ag}^{+}$ion over the concentration range of $1.0 \times 10^{-6}$ to $1.0 \times 10^{-1} \mathrm{M}$ with a lower detection limit of $6.0 \times 10^{-7} \mathrm{M}$. The electrode possesses a Nernstian slope of $59.7 \mathrm{mV} \mathrm{decade}{ }^{-1}$ and a fast response time of $\leq 17 \mathrm{~s}$ and can be used for at least 2 months without any observable deviation. The proposed electrode displayed very good selectivity for $\mathrm{Ag}^{+}$ion with respect to $\mathrm{NH}_{4}{ }^{+}$and alkali, alkaline earth and some common transition metal ions. The practical utility of the electrode has been demonstrated by its use as the indicator electrode in the potentiometric titration of an $\mathrm{AgNO}_{3}$ solution with a NaI solution and in determination of the silver content of a developed radiological film.
\end{abstract}

(Received October 14, 2003; Accepted December 16, 2003)

\section{Introduction}

In the past few decades, considerable efforts have led to the development of new sensors for fast, accurate, reproducible and selective determination of many important ions..$^{1,2}$ The introduction of new ion selective electrodes (ISEs) has promoted fundamental developments in potentiometry. ${ }^{3-7}$ Potentiometric detectors based on ISEs offer advantages such as selectivity, sensitivity, good precision, simplicity, wide linear concentration range and long lifetime. The key ingredient of poly(vinyl chloride) (PVC) membrane electrodes is the incorporated ionophore, which defines the selectivity of the electrodes via selective complex formation with the cation of interest. Silver ion is a precious metal ion, mainly due to its greater inertness. ${ }^{8}$ The development of fast and selective techniques for the separation and determination of precious metal ions such as $\mathrm{Ag}^{+}$is of considerable economic and environmental concern. ${ }^{9,10}$ Thus, the quest for new neutral ionophores capable of specific and effective recognition of such metal ions is a topic of current interest. ${ }^{11-25}$ Besides conventionally constructed electrodes, the coated wire electrodes (CWEs) have become attractive because of their simple fabrication, high dynamic range and enhanced possibility of miniaturization. Since the development of CWEs by Cattrall and Freiser, ${ }^{26}$ several CWEs have been reported. ${ }^{27-33}$

Recently, we have used neutral ionophores in the construction of CWEs for $\mathrm{Hg}^{2+},{ }^{34} \mathrm{Ni}^{2+},{ }^{35}$ and $\mathrm{Pb}^{2+} .{ }^{36}$ In the present paper, we report the use of Schiff-base $N, N^{\prime}$-bis(2-thienylmethylene)-1,2diaminobenzene as an excellent neutral ionophore for the

$\doteqdot$ To whom correspondence should be addressed.

E-mail: hrzare@yazduni.ac.ir preparation of a high selective CWE for the potentiometric determination of $\mathrm{Ag}^{+}$ion over a wide concentration range. In this Schiff base, nitrogen and sulfur atoms act as donor atoms and coordinate effectively with silver ions, because the soft heavy metal ions, such as $\mathrm{Ag}^{+}, \mathrm{Pb}^{2+}$ and $\mathrm{Hg}^{2+}$, display great affinity to soft coordination centers like nitrogen and sulfur atoms. $^{34-42}$

\section{Experimental}

\section{Reagents and apparatus}

Reagent grade poly(vinyl chloride) (PVC), dibutyl phthalate (DBP), acetophenone (AP), benzyl acetate (BA) and oleic acid (OA) were purchased from Fluka. All other chemicals and solvents were analytical reagent grade and were purchased from Merck and used without any further purification. Doubly distilled water was used throughout the experiments. The ionophore $\quad N, N^{\prime}$-bis(2-thienylmethylene)-1,2-diaminobenzene (BTMD) was synthesized. All potentiometric measurements were carried out at $25^{\circ} \mathrm{C}$, using a Metrohm pH/ion Meter Model 691. An Azarelectrode double junction $\mathrm{Ag} / \mathrm{AgCl}$ reference electrode containing $3.0 \mathrm{M}$ potassium nitrate in the outer compartment was used in conjunction with the proposed electrode. The electrochemical cell for measurement can be represented as follows:

$\mathrm{Ag}|\mathrm{AgCl}| \mathrm{KCl}(3.0 \mathrm{M}) \| \mathrm{KNO}_{3}(3.0 \mathrm{M})||$ test solution | PVC membrane | Pt

The steady-state potential $( \pm 1 \mathrm{mV})$ was recorded in all measurements. An atomic absorption spectrometer (Buck Scientific Model VGP 210) with an air-acetylene flame was used as a reference method for determination of silver in radiological film samples. Measurement was performed 


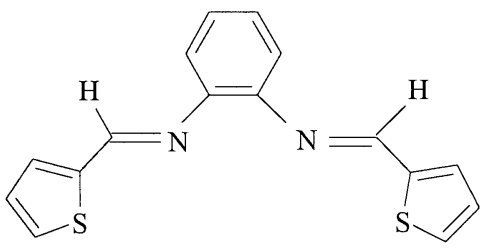

Fig. 1 The structure of $N, N^{\prime}$-bis(2-thienylmethylene)-1,2-diaminobenzene (BTMD).

according to the manufacturer's directions.

\section{Synthesis of ionophore}

The Schiff-base ligand of $N, N^{\prime}$-bis(2-thienylmethylene)-1,2diaminobenzene (BTMD) was synthesized in the usual manner by reaction of thiophene-2-carbaldehyde with phenylene-1,2diamine in a $2: 1 \mathrm{~mol}$ ratio in methanol as follows: thiophene-2carbaldehyde $(0.02 \mathrm{~mol}, 0.74 \mathrm{~g})$ and phenylene-1,2-diamine $(0.01 \mathrm{~mol}, 1.08 \mathrm{~g})$ were placed in a $50 \mathrm{ml}$ round-bottom flask equipped with a condenser and a magnetic bar. Methanol (20 $\mathrm{ml}$ ) was then added to the mixture, and the mixture was refluxed for $3 \mathrm{~h}$ while stirring. The solvent was evaporated and the viscous ligand was kept under vacuum while heating gently. The viscous Schiff-base ligand of BTMD (Fig. 1) was then solidified upon standing for a few days to obtain a brown product quantitatively with $\mathrm{mp}=144-145^{\circ} \mathrm{C}$. The structure of BTMD was confirmed by ${ }^{1} \mathrm{H}$ NMR and IR spectroscopy.

${ }^{1} \mathrm{H}$ NMR $\left(\mathrm{CDCl}_{3}, \mathrm{ppm}\right): 7.8$ (m, 4H, phenyl), $7.06(\mathrm{~m}, 2 \mathrm{H}$, $\left.\mathrm{C}_{4} \mathrm{H}_{3} \mathrm{~S}\right), 7.34\left(\mathrm{~m}, 2 \mathrm{H}, \mathrm{C}_{4} \mathrm{H}_{3} \mathrm{~S}\right), 7.45\left(\mathrm{~m}, 2 \mathrm{H}, \mathrm{C}_{4} \mathrm{H}_{3} \mathrm{~S}\right), 8.51(\mathrm{~s}, 2 \mathrm{H}$, $\mathrm{CH}=\mathrm{N})$; IR (KBr, cm$\left.{ }^{-1}\right): 3090$ (m), 3070 (m), 3065, 2920, 2940 (m), 2860 (m), $2830(\mathrm{~m}), 1920(\mathrm{~m}), 1830(\mathrm{w}), 1645(\mathrm{C}=\mathrm{N}, \mathrm{s})$, 1525 (w), 1445 (s), 1432 (s), 1351 (m), 1330 (m), 1317 (s), $1241(\mathrm{~m}), 1200(\mathrm{~m}), 1090(\mathrm{~s}), 1071(\mathrm{~m}), 1052(\mathrm{~s}), 951(\mathrm{~s}), 916$ (m), 865, 855, 845, 840 (m), 745, 735 (s), 710 (s), 650 (w), 580 (w), $400(\mathrm{~m}), 320(\mathrm{w})$; Elemental Analysis. Calculated for $\mathrm{C}_{16} \mathrm{H}_{12} \mathrm{~N}_{2} \mathrm{~S}_{2}$ : C 64.84, H 4.08 and N 9.45; Found: C 64.61; H 4.12 and $\mathrm{N} 9.56 \%$.

\section{Electrode preparation}

The PVC membrane solution was prepared by through mixing of ionophore (BTMD, $6 \mathrm{mg}$ ), plasticizer (DBP, $57 \mathrm{mg}$ ), additive (OA, $12 \mathrm{mg}$ ) and powdered PVC (25 mg), in $5 \mathrm{ml}$ of THF. The resulting mixture was transferred into a glass dish of $2 \mathrm{~cm}$ diameter and the solvent was evaporated slowly until an oily concentrated mixture was obtained. A platinum-wire, about 1 $\mathrm{cm}$ long and $1 \mathrm{~mm}$ in diameter with a spherical head, sealed into the end of a glass tube and soldered onto a shielded cable, was dipped into the membrane solution three times, and the solvent was evaporated each time at room temperature. A membrane was formed on the platinum surface; it was allowed to set for 2 $\mathrm{h}$. The electrodes were then rinsed with water and finally conditioned by soaking in $1.0 \times 10^{-2} \mathrm{M} \mathrm{AgNO}_{3}$ solution for 24 h. The coating solutions are stable for several weeks and can be used for the construction of new membranes.

\section{Results and Discussion}

\section{Response behavior}

The BTMD as a carrier was found to be highly sensitive to $\mathrm{Ag}^{+}$with respect to several other metal ions. Therefore, we studied in detail the performance of membrane coated platinumwire electrode (MCPWE) containing this ionophore for $\mathrm{Ag}^{+}$in
Table 1 Optimization of membrane ingredients

\begin{tabular}{|c|c|c|c|c|c|c|}
\hline \multirow{2}{*}{$\begin{array}{c}\text { Membrane } \\
\text { No. }\end{array}$} & \multicolumn{4}{|c|}{ Composition, $\%$} & \multirow{2}{*}{$\begin{array}{l}\text { Slope/ } \\
\text { mV } \\
\text { decade }^{-1}\end{array}$} & \multirow{2}{*}{$\begin{array}{c}\text { Linear } \\
\text { range/M }\end{array}$} \\
\hline & BTMD & PVC & OA & Plasticizer & & \\
\hline 1 & 5 & 25 & 10 & 60 (DBP) & 43.0 & $10^{-6}-10^{-1}$ \\
\hline 2 & 6 & 25 & 10 & 60 (DBP) & 42.4 & $10^{-6}-10^{-1}$ \\
\hline 3 & 7 & 25 & 8 & 60 (DBP) & 46.1 & $10^{-6}-10^{-1}$ \\
\hline 4 & 4 & 25 & 12 & 59 (DBP) & 51.6 & $10^{-5}-10^{-1}$ \\
\hline 5 & 5 & 33 & 12 & 50 (DBP) & 41.0 & $10^{-5}-10^{-1}$ \\
\hline 6 & 5 & 30 & 12 & 53 (DBP) & 45.9 & $10^{-5}-10^{-1}$ \\
\hline 7 & 5 & 27 & 12 & 56 (DBP) & 49.2 & $10^{-5}-10^{-1}$ \\
\hline 8 & 6 & 25 & 12 & 57 (DBP) & 59.7 & $10^{-6}-10^{-1}$ \\
\hline 9 & 5 & 20 & 12 & 63 (DBP) & 55.5 & $10^{-6}-10^{-1}$ \\
\hline 10 & 6 & 25 & 12 & $57(\mathrm{BA})$ & 46.0 & $10^{-6}-10^{-1}$ \\
\hline 11 & 5 & 20 & 12 & $63(\mathrm{BA})$ & 39.0 & $10^{-6}-10^{-1}$ \\
\hline 12 & 6 & 25 & 12 & 57 (AP) & 36.1 & $10^{-6}-10^{-1}$ \\
\hline 13 & 5 & 20 & 12 & 63 (AP) & 35.6 & $10^{-6}-10^{-1}$ \\
\hline 14 & - & 25 & 12 & 63 (DBP) & 27.0 & $10^{-5}-10^{-1}$ \\
\hline 15 & 5 & 32 & - & 63 (DBP) & 39.2 & $10^{-6}-10^{-1}$ \\
\hline
\end{tabular}

aqueous solutions. The interaction mechanism of BTMD with $\mathrm{Ag}^{+}$was studied. The Schiff-base ligand $(0.50 \mathrm{~g}, 1.69 \mathrm{mmol})$ was dissolved in $20 \mathrm{ml}$ of ethanol, and the solution was refluxed. To this hot solution was added silver nitrate $(0.29 \mathrm{~g}$, $1.69 \mathrm{mmol}$ ) dissolved in $20 \mathrm{ml}$ of ethanol. Refluxing was continued for $2 \mathrm{~h}$. When the solution was cooled, a solid crystalline material was obtained. This was filtered, washed with chloroform and dried in vacuum, and purified by recrystallization from ethanol. The IR spectra of silver complex, [Ag-BTMD]NO $\mathrm{N}_{3}$, show a significant change in some important bands from the free Schiff-base ligand. For example, the free ligand exhibits a $v(\mathrm{C}=\mathrm{N})$ stretch $1645 \mathrm{~cm}^{-1}$. In the complex, this band shifted to lower frequency and appears at $1605-1570 \mathrm{~cm}^{-1}$, indicating the coordination of azomethine nitrogen to the $\mathrm{Ag}^{+}$. The $v(\mathrm{C}-\mathrm{S})$ band appears at $865 \mathrm{~cm}^{-1}$ in the spectra of the ligand and is of medium intensity at $850 \mathrm{~cm}^{-1}$ in the spectra of the complex. This shift to a lower wavenumber suggested that the sulfurs are the bonding sites in the complex. The presence of several bands of medium intensity in the 3090 $2860 \mathrm{~cm}^{-1}$ region indicated the existence of $\mathrm{C}-\mathrm{H}$ groups of the tetra dentate Schiff-base ligand.

\section{Influence of membrane composition}

It is well known that the selectivity, linear dynamic range and sensitivity obtained for a given ionophore depend significantly on the membrane composition and the nature of the solvent mediator and additives used. ${ }^{1-7}$ Thus, the influences of some important features of PVC membrane such as the membrane composition, nature and amount of plasticizer and amount of oleic acid as lipophilic additives on the potential response of the silver electrodes were investigated; the results are summarized in Table 1. Since the nature of plasticizer influences the dielectric constant of the membrane phase and the mobility of the ionophore molecules and its complex, ${ }^{43,44}$ it is expected to play an important role in determining the characteristics of the ion-selective electrode (ISE). Thus, two sets of membranes of similar composition (i.e., Nos. 8, 10 and 12 and Nos. 9, 11 and 13) but with three different plasticizers having different dielectric constants, namely, BA $(\varepsilon=5.1)$, DBP $(\varepsilon=8.5)$ and $\mathrm{AP}(\varepsilon=17.4)$, were prepared and tested. As can be seen from Table 1, among the three different plasticizers tried, the use of DBP and BA with lower relative dielectric constants in the series gives the larger response slopes than that of the higher relative dielectric constant AP. This is consistent with the 


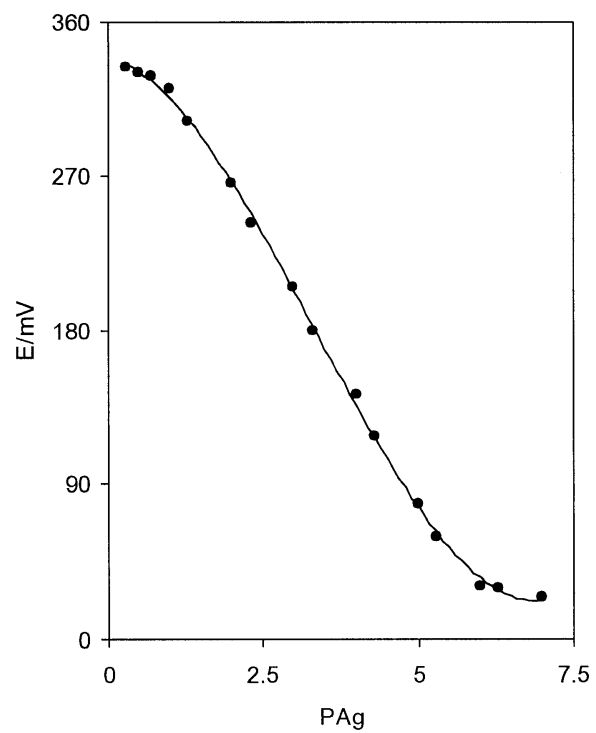

Fig. 2 Calibration graph of the $\mathrm{Ag}^{+}$-selective electrode based on BTMD.

literature that, in sensors for monovalent cations, the use of relatively non-polar membrane material can improve the cation response. ${ }^{45}$ The DBP gives the best sensitivity among the three plasticizers, and therefore was used in all subsequent studies. The plasticizer/PVC ratios of $1.5-2.4$ were examined. The membrane prepared with a plasticizer/PVC ratio of about 2.3 was found to have the best sensitivity and the widest linear range. It is well known that the presence of lipophilic anionic sites in cation-selective membrane electrodes not only reduce the ohmic resistance ${ }^{46}$ and improve the response behavior and selectivity ${ }^{47,48}$ but also, in cases where the extraction capability of the ionophore is poor, enhance the sensitivity of the membrane electrode. ${ }^{45}$ Moreover, the lipophilic additives may catalyze the exchange kinetics at the sample-membrane interface. ${ }^{49}$ In order to investigate the effect of anionic sites in the membrane system with DBP as plasticizer, we studied the influence of the OA concentration. As seen in Table 1, the electrode without OA (No. 15) gives a response of $39.2 \mathrm{mV}$ per decade in the $\mathrm{Ag}^{+}$ion activity range of $10^{-6}-10^{-1} \mathrm{M}$. However, the incorporation of this anionic additive into the membrane resulted in a Nernstian slope of $59.7 \mathrm{mV}$ per decade (No. 8) in the $\mathrm{Ag}^{+}$ion activity range of $10^{-6}-10^{-1} \mathrm{M}$. In the present work, we found that the use of $12 \%$ OA resulted in a Nernstian behavior and improved linearity, selectivity and stability of the electrode responses. The amount of ionophore BTMD was also found to affect the sensitivity of the membrane electrodes (Nos. 4,8 and 9). The sensitivity of the electrode response increases with increasing ionophore content until the value of $6 \%$ is reached (No. 8). The blank membrane without ligand containing PVC, DBP and OA was also prepared (No. 14) and its potential response toward varying concentrations of $\mathrm{Ag}^{+}$ion was measured. As is obvious from Table 1, a linear response for $\mathrm{Ag}^{+}$within the concentration range from $1.0 \times 10^{-5}$ to $1.0 \times$ $10^{-1} \mathrm{M}$ and slope was non-Nernstian response ( $c a .27 .0 \mathrm{mV}$ decade $^{-1}$ ). Among the different compositions studied, the membrane incorporating 25\% PVC, 57\% DBP, $12 \% \mathrm{OA}$ and $6 \%$ BTMD exhibits the best response characteristics. Therefore, this composition was used to study various operation parameters of the electrode, such as working concentration range, sensitivity, lifetime, response time and $\mathrm{pH}$.

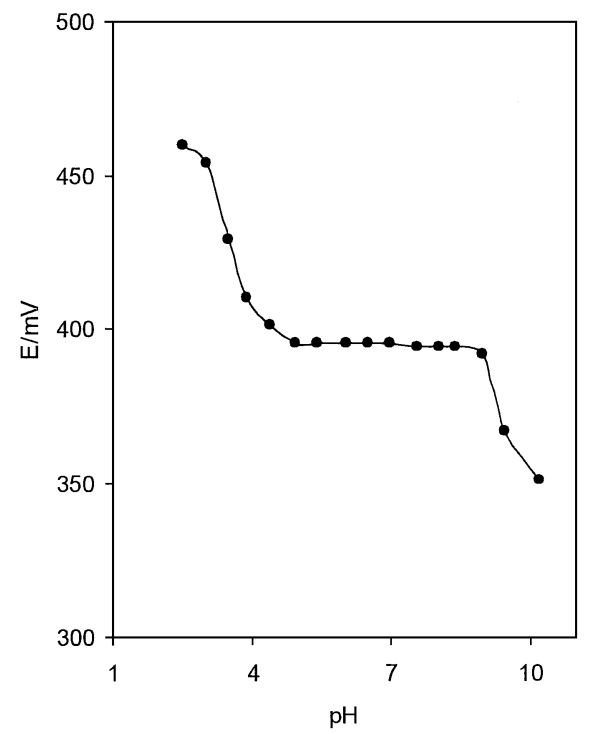

Fig. 3 Effect of $\mathrm{pH}$ of the test solution on the potential response of the coated platinum-wire electrode (MCPWE) based on BTMD, at a silver concentration of $1.0 \times 10^{-4} \mathrm{M}$.

\section{Response characteristics of the electrodes}

The potential response of the optimized MCPWE to varying concentration of $\mathrm{Ag}^{+}$ions was examined. The calibration plot is shown in Fig. 2; it indicates a linear range from $1.0 \times 10^{-6}$ to 1.0 $\times 10^{-1} \mathrm{M}(R=0.9991)$ with a Nernstian slope of $59.7 \mathrm{mV}$ per decade of $\mathrm{Ag}^{+}$concentration. The practical limit of detection, defined as the concentration of silver ion obtained from the intersection of two extrapolated segments of the calibration graph, was about $6.0 \times 10^{-7} \mathrm{M}$. The optimum equilibration times for MCPWE in the presence of $1.0 \times 10^{-2} \mathrm{M}$ silver nitrate was $24 \mathrm{~h}$, after which the electrode would generate stable potentials in contact with silver solutions. The standard deviation of 22 replicate measurements at $1.0 \times 10^{-3}$ and $1.0 \times$ $10^{-4} \mathrm{M} \mathrm{Ag}^{+}$were \pm 0.47 and $\pm 0.49 \mathrm{mV}$, respectively. The time required for the electrodes to reach a potential response within $\pm 1 \mathrm{mV}$ of the final equilibrium value after successive immersion in a series of $\mathrm{Ag}^{+}$solutions, each having 10-fold difference in concentration, was studied. The static response time of the electrode was found to be $\leq 17$ s over the entire concentration range. The membrane electrode was used practically for two months without any significant change in response time, slope or detection limit.

The influence of $\mathrm{pH}$ of the test solution $\left(1.0 \times 10^{-4} \mathrm{M} \mathrm{AgNO}_{3}\right)$ on the potential response of the $\mathrm{Ag}^{+}$selective electrode was examined over the $\mathrm{pH}$ range of $2.5-10.2$. The $\mathrm{pH}$ was adjusted by introducing small drops of solutions of nitric acid or sodium hydroxide; the results are shown in Fig. 3. As can be seen, the potential remained constant from $\mathrm{pH} 5.0$ to 9.0. This implies that the proposed electrode can be used to measure a wide range of environmental and industrial water samples without $\mathrm{pH}$ adjustment. However, outside this range, the electrodes' responses change drastically. The observed drifts at higher $\mathrm{pH}$ values could be due to some silver hydroxide formation in sample solutions and the observed increases at low-pH values indicate that the membrane sensors respond to hydrogen ions.

\section{Potentiometry selectivity}

The selectivity behavior is obviously one of the important characteristics of ion-selective electrodes, determining whether reliable measurement in the target sample is possible. The 
Table 2 Potentiometric selectivity coefficient $\left(K_{\mathrm{Ag}, \mathrm{M}}^{\text {pot. }}\right)$ values of the $\mathrm{Ag}^{+}$ion-selective electrode toward various cations

\begin{tabular}{cccc}
\hline Interfering ion & \multicolumn{1}{c}{$K$ Pbo, $\mathrm{M}$} & Interfering ion & \multicolumn{1}{c}{$K{ }_{\mathrm{Pb}, \mathrm{M}}^{\mathrm{Pot}}$} \\
\hline $\mathrm{K}^{+}, \mathrm{Na}^{+}$ & $1.5 \times 10^{-4}$ & $\mathrm{Ba}^{2+}, \mathrm{Ca}^{2+}$ & $1.2 \times 10^{-3}$ \\
$\mathrm{Cs}^{+}$ & $5.2 \times 10^{-3}$ & $\mathrm{Cu}^{2+}$ & $4.0 \times 10^{-4}$ \\
$\mathrm{NH}_{4}{ }^{+}$ & $2.0 \times 10^{-3}$ & $\mathrm{Zn}^{2+}, \mathrm{Cd}^{2+}$ & $1.0 \times 10^{-3}$ \\
$\mathrm{Tl}^{+}$ & $3.8 \times 10^{-3}$ & $\mathrm{Sr}^{2+}, \mathrm{Mg}^{2+}$ & $1.6 \times 10^{-4}$ \\
$\mathrm{~Pb}^{2+}$ & $2.0 \times 10^{-4}$ & $\mathrm{Hg}^{2+}$ & $1.7 \times 10^{-2}$ \\
$\mathrm{Ni}^{2+}$ & $2.3 \times 10^{-3}$ & $\mathrm{Fe}^{3+}$ & $7.0 \times 10^{-3}$ \\
$\mathrm{Co}^{2+}$ & $1.5 \times 10^{-3}$ & $\mathrm{Al}^{3+}$ & $3.4 \times 10^{-3}$ \\
\hline
\end{tabular}

selectivity of the proposed silver ion-selective electrodes over other cations $\left(\mathrm{M}^{n+}\right)$ was important; their potential responses were investigated in the presence of a wide variety of interfering foreign cations using the mixed solution method (MSM)..$^{50,51}$ In this mixed solution method, the interfering ion at different concentrations was added to a $1.0 \times 10^{-3} \mathrm{M}$ silver(I) ion solution, and the change of potential for each adding was recorded. Then, the selectivity coefficients, $K_{\mathrm{Ag}, \mathrm{M}}^{\text {pot }}$, were evaluated based on the following equation:

$$
K_{\mathrm{Ag}, \mathrm{M}}^{\mathrm{pot}} \cdot a_{\mathrm{M}}^{1 / n}=a_{\mathrm{Ag}}\left\{\exp \left[\left(E_{2}-E_{1}\right)(F / R T)\right]\right\}-a_{\mathrm{Ag}},
$$

where $a_{\mathrm{Ag}}$ is the activity of the primary ion, $a_{\mathrm{M}}$ the activity of interfering ion with a charge of $n, E_{1}$ the potential measured when only silver(I) ion is present, $E_{2}$ the potential responsive to the primary ion in the presence of interfering ion and $K_{\mathrm{Ag}, \mathrm{M}}^{\mathrm{pot}}$ is the selectivity coefficient. According to Eq. (1), the $K_{\mathrm{Ag}, \mathrm{M}}^{\mathrm{pot}}$ values for diverse ions can be evaluated from the slope of the graph of $a_{\mathrm{Ag}}\left\{\exp \left[\left(E_{2}-E_{1}\right)(F / R T)\right]\right\}-a_{\mathrm{Ag}}$ versus $K_{\mathrm{Ag}, \mathrm{M} \text {. }}^{\text {pot. }}$ The values of selectivity coefficients are summarized in Table 2. The data given in Table 2 revealed that the selectivity coefficients obtained by the proposed electrode for all cations tested are on the order of $10^{-3}$, which indicated very good selectivity for $\mathrm{Ag}^{+}$ion against alkali, alkaline earth and some common transition metal ions. Such remarkable selectivity of the proposed $\mathrm{Ag}^{+}$ion-selective electrode over other metal ions reflects the high affinity of the sulfur and nitrogen coordination sites of the ionophore BTMD toward the $\mathrm{Ag}^{+}$ion and can be used successfully as a sensing agent for silver-selective electrodes. ${ }^{37-42}$ However, the soft heavy metal $\mathrm{Hg}^{2+}$ is more likely to complex BTMD containing soft donor atoms such as $\mathrm{S}$ and $\mathrm{N}$ atoms. ${ }^{52}$ This action would lead to some interference toward $\mathrm{Ag}^{+}$ions, although value of the corresponding selectivity coefficient for $\mathrm{Ag}^{+}$against $\mathrm{Hg}^{2+}$ is still small. Therefore, the selectivity of the present ion-selective electrode is good enough to assure analytical applications. The conventional silver ionselective electrodes based on the calixarene derivatives and crown ether neutral carriers containing soft donor atoms, such as $\mathrm{N}$ and $\mathrm{S}$ atoms, often suffer from the strong interference by $\mathrm{Hg}^{2+} .{ }^{53-55}$ It should also be noted that the present silver ionselective electrode did not suffer from the response of $\mathrm{Na}^{+}$, which is also troublesome in the measurement of biological fluids or sample containing a lot of salt, ${ }^{37-41,56}$ or that of $\mathrm{Pb}^{2+}$ which is a major interfering ion for the determination of silver ions using the membrane electrodes based on neutral carriers containing soft donor atoms. ${ }^{34,55,57}$

\section{Analytical applications}

The proposed membrane electrodes were found to work well under laboratory conditions. The coated-wire electrode was used as an indicator electrode in the successful titration of an

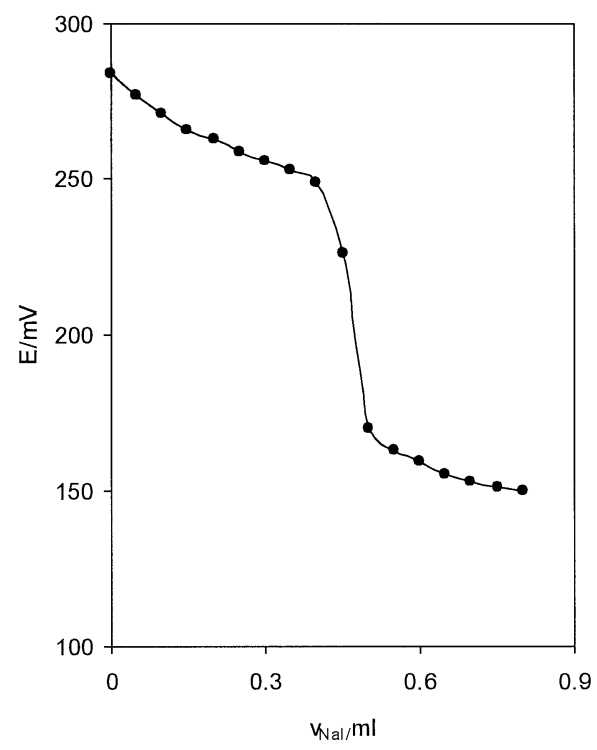

Fig. 4 Potentiometric titration curve of $50.0 \mathrm{ml}$ of $1.0 \times 10^{-4} \mathrm{M}$ $\mathrm{AgNO}_{3}$ with $1.0 \times 10^{-2} \mathrm{M} \mathrm{NaI}$, using the MCPWE as an indicator electrode.

$\mathrm{Ag}^{+}$solution $\left(50.0 \mathrm{ml}, 1.0 \times 10^{-4}\right)$ with an $\mathrm{I}^{-}$solution $\left(1.0 \times 10^{-2}\right.$ M). The resulting titration curve is shown in Fig. 4. It is seen that the amount of silver ion can be accurately determined with the electrode. The electrode was also successfully applied to the direct determination of silver content of a piece of developed radiological film. To $2.0 \mathrm{~g}$ of the film sample was added $20 \mathrm{ml}$ of $6.0 \mathrm{M} \mathrm{HNO}_{3}$ and the mixture was boiled for 30 min. The resulting mixture was then filtered and the filtrate was neutralized with $1.0 \mathrm{M}$ sodium hydroxide solution and diluted to $50.0 \mathrm{ml}$ with distilled water. The silver content of the final solution was determined by the proposed electrode using the standard addition method and also by atomic absorption spectrometry (AAS), as a reference method. The comparison of the results obtained from three measurements $(1.40 \pm 0.04) \times$ $10^{-3} \mathrm{M}$, and the certified value, $(1.35 \pm 0.03) \times 10^{-3} \mathrm{M}$, shows that the present electrode can be used in determination of $\mathrm{Ag}^{+}$in real samples.

\section{Conclusion}

The membrane coated platinum-wire electrode (MCPWE), prepared with $\quad N, N^{\prime}$-bis(2-thienylmethylene)-1,2diaminobenzene (BTMD) under optimal PVC-membrane ingredients revealed a Nernstian response over a wide silver concentration range, fast response time, reproducibility and long lifetime. The present silver ion-selective electrode displayed very good selectivity for $\mathrm{Ag}^{+}$ion with respect to $\mathrm{NH}_{4}{ }^{+}$and alkali, alkaline earth and some common transition metal ions. In particular the present $\mathrm{Ag}^{+}$-selective electrode exhibited very low responses toward $\mathrm{Pb}^{2+}$, which is the major interfering ion for the determination of silver ions using the conventional silver ion-selective electrodes based on neutral carriers containing soft donor atoms such as $\mathrm{N}$ and $\mathrm{S}$ atoms. ${ }^{34,55,57}$ The electrode was used as an indicator electrode for determination of $\mathrm{Ag}^{+}$solution with $\mathrm{I}^{-}$solution. The membrane electrode was successfully applied to the determination of silver content in real samples. 


\section{References}

1. E. Bakker, P. Bühlmann, and E. Pretsch, Chem. Rev., 1997, 97, 3083.

2. P. Bühlmann, E. Pretsch, and E. Bakker, Chem. Rev., 1998, 98, 1593.

3. A. Ohki, J. P. Lu, and R. A. Bartsch, Anal. Chem., 1994, $66,4432$.

4. S. Daunert and L. G. Bachas, Anal. Chem., 1990, 62, 1428.

5. R. S. Hutchins, P. Molina, M. Alajarin, A. Vidal, and L. G. Bachas, Anal. Chem., 1994, 66, 3188.

6. A. K. Jain, V. K. Gupta, L. P. Singh, and U. Khurana, Analyst, 1997, 122, 583.

7. Z. Xia, I. H. A. Badr, S. L. Plummer, L. Cullen, and L. G. Bachas, Anal. Sci., 1998, 14, 169.

8. A. T. Yordanov and D. M. Roundhill, Coord. Chem. Rev., 1998, 170, 93.

9. Environmental Protection Agency, Ambient Water Quality Criteria for Silver, EPA-4405-80-071, 1980, Office of Water Regulations, Washington, D.C.

10. E. Meian (ed.), "Metals and Their Compounds in Environment', 1991, VCH, New York.

11. M. H. Mashhadizadeh and M. Shamsipur, Anal. Chim. Acta, 1999, 381, 111.

12. D. Siswanta, K. Nagatsuka, H. Yamada, K. Kumakura, H. Hisamoto, Y. Shichi, and K. Suzuki, Anal. Chem., 1996, $68,4166$.

13. M. R. M. Bates, T. J. Cardwell, R. W. Cattrall, L. W. Deady, and C. G. Gregorio, Talanta, 1995, 42, 999.

14. Y. Masuda, K. Yakabe, Y. Shibutani, and T. Shono, Anal. Sci., 1994, 10, 491.

15. J. Casabo, T. Flor, M. I. Romero, F. Teixidor, and C. Perezjimenez, Anal. Chim. Acta, 1994, 294, 207.

16. A. Jiménez-Morales, J. C. Galván, and P. Aranda, Electrochim. Acta, 2002, 47, 2281.

17. Z. Brzozka, P. L. H. Cobben, D. Reinhouldt, J. J. H. Edema, J. Bultler, and R. M. Kellogg, Anal. Chim. Acta, 1993, 273, 139.

18. K. M. O’Connor, G. Svehla, S. J. Harris, and M. A. Mc-Kervey, Anal. Proc., 1992, 30, 137.

19. M. R. M. Bates, T. J. Cardwell, R. W. Cattrall, L. W. Deady, and K. Murphy, Aust. J. Chem., 1991, 44, 1603.

20. F. Teixidor, M. A. Flores, L. Escriche, C. Vinas, and J. Casabo, J. Chem. Soc., Chem. Commun., 1994, 963.

21. K. Kimura and T. Shono, in "Cation Binding by Macrocycles", ed. Y. Inoue and G. W. Gokel, 1990, Marcel-Dekker, New York.

22. Y. Umezawa, "CRC Handbook of Ion-Selective Electrodes," 1990, CRC Press, Boca Raton, FL.

23. M. Aghamohammadi and N. Alizadeh, Anal. Chim. Acta, 2003, 480, 299.

24. M. Shamsipur, M. Yousefi, M. Hosseini, and M. R. Ganjali, Anal. Chem., 2002, 74, 5538.

25. D. Xu and T. Katsu, Anal. Chim. Acta, 2001, 443, 235.

26. R. W. Cattrall and H. Freiser, Anal. Chem., 1971, 43, 1905.

27. R. W. Cattrall and P. C. Pui, Anal. Chem., 1975, 47, 93.
28. R. W. Cattrall and P. C. Pui, Anal. Chim. Acta, 1976, 83, 355.

29. R. W. Cattrall and P. C. Pui, Anal. Chem., 1976, 48, 552.

30. R. W. Cattrall and P. C. Pui, Anal. Chim. Acta, 1979, 87, 419.

31. P. W. Alexander and J. P. Joseph, Talanta, 1981, 28, 931.

32. R. W. Cattrall and G. L. Lee, Anal. Chim. Acta, 1980, 116, 391.

33. J. A. Ortuno, T. Rerez Ruiz, and C. Sanchez-Pedreno, Anal. Chim. Acta, 1986, 185, 351.

34. M. Mazloum, M. K. Amini, and I. MohammadpoorBaltork, Sens. Actuators B, 2000, 63, 80.

35. M. Mazloum, M. Salavati-Niassary, and M. K. Amini, Sens. Actuators B, 2002, 82, 259.

36. M. K. Amini, M. Mazloum, and A. A. Ensafi, Fresenius J. Anal. Chem., 1999, 364, 690.

37. K. M. O'Connor, G. Svehla, S. J. Harris, and M. A. Mc-Kervey, Talanta, 1992, 39, 1549.

38. E. Malinowska, Z. Brózka, K. Kasiura, R. J. M. Egberink, and D. N. Reinhoudt, Anal. Chim. Acta, 1994, $298,245$.

39. E. Malinowska, Z. Brózka, K. Kasiura, R. J. M. Egberink, and D. N. Reinhoudt, Anal. Chim. Acta, 1994, 298, 253.

40. L. Chen, X. He, B. Zhao, and Y. Lui, Anal. Chim. Acta, 2000, 417, 51.

41. X. Zeng, L. Weng, L. Chen, X. Leng, Z. Zhang, and X. He, Tetrahedron Lett., 2000, 41, 4917.

42. K. Kimura, S. Yajima, K. Tatsumi, M. Yokoyama, and M. Oue, Anal. Chem., 2000, 72, 5290.

43. X. Yang, N. Kumar, H. Chi, D. B. Hibbert, and P. N. W. Alexander, Electroanalysis, 1997, 9, 549.

44. S. K. Norov, M. T. Gulamova, A. F. Zhukov, G. M. Norova, and Y. G. Mamedova, Zh. Anal. Khim., 1988, 43, 777.

45. D. Ammann, W. E. Morf, P. Anker, P. C. Meier, E. Pretsch, and W. Simon, Ion Sel. Electrode Rev., 1983, 5, 3.

46. U. Schaller, E. Bakker, U. E. Spichiger, and E. Pretsch, Anal. Chem., 1994, 66, 391.

47. Y. Masuda, Y. Zhang, C. Yan, and B. Li, Talanta, 1998, 46, 203.

48. S. S. M. Hassan, W. H. Mahmud, and A. H. M. Othmani, Talanta, 1997, 44, 1087.

49. R. Eugster, P. M. Gehrig, W. E. Morf, U. E. Spichiger, and W. Simon, Anal. Chem., 1991, 63, 2285.

50. K. Srinivasan and G. A. Rechnitz, Anal. Chem., 1969, 41, 1203.

51. Y. Umezawa, K. Umezawa, and H. Sato, Pure Appl. Chem., 1995, 67, 507.

52. P. R. Pearson, J. Am. Chem. Soc., 1963, 85, 3533.

53. L. Chen, X. Zeng, H. Ju, X. He, and Z. Zhang, Microchem. J., 2000, 65, 129.

54. M. H. Mashhadizadeh and M. Shamsipur, Anal. Chim. Acta, 1999, 381, 111.

55. M.-T. Lai and J.-S. Shih, Analyst, 1986, $111,891$.

56. M. Que, K. Akama, K. Kimura, M. Tanaka, and T. Shono, J. Chem. Soc., Perkin Trans., 1989, 1, 1675.

57. L. Chen, X. He, B. Zhao, and Y. Liu, Anal. Chim. Acta, 2000, 417, 51 . 